\section{EMPREGO DA GLICERINA COMO ELEMENTO AUXILIAR NA CONSERVAÇĀO DO VIRUS DA FEBRE AFTOSA}

\author{
CESAR EDUARDO ENRIQUEZ ROZAS \\ Médico Veterinário \\ Ministério da Agricultura \\ JOSÉ DE ANGELIS CÔRTES \\ Professor Livre-Docente \\ Faculdade de Medicina Veterinária e \\ Zootecnia da USP

\section{SILVIO ARRUDA VASCONCELLOS \\ Professor Assitente Doutor \\ Faculdade de Medicina Veterinária e Zootecnia da USP} \\ FUMIO HONMA ITO \\ Auxiliar de Ensino \\ Faculdade de Medicina Veterinária e \\ Zootecnia da USP
}

ROZAS, C.1.1 CORTIS, J 1.: VASCONCILLOS. S. I. ITO. I II limprego da glicerina como elemento auviliar na conservalcẽos do vírus da febre aftosil. Rev.Fac.Med.vet.Zootec.UnivS. Paulo, 18(2): 147-151, 1981

RESUMO: Duas porções de uma mesma suspensão de vírus, tipo ' $C$ " Waldmann, Subtipo 'C3' Indaial, da febre aftosa foram adicionadas a irual volume, respectivamente de glicerina e de diluente comum iSalina de larrle adicionada de 2.000 UI de penicilina ( $\mathrm{i}$ potássica es 2,0 miligramas de sulfuto (le estreptomicina por mililitro), c estocada a $-20^{\circ} \mathrm{C}$. Os resultados obtidos nas provas de Titulaçajo sucessivas realizadas, em camundongos lactentes, imediatamente após e as 117. 150,185 \& 213 dias de sua preparaçāo revelam uma maior estabiliclade da suspensĩo ad icionada de glicerina.

UNITERMOS: (iliccrina*: Febre aftosa ${ }^{\text {it }}$ : Vírus"

\section{INTRODUÇÃO}

A conservação de espécimens do virus da febre aftosa, mantendo inalteradas suas caracteristicas de infectividade, assume grande importància, particularmente, quando se tem a intenção de minimizar as fontes de variação em testes de potência de vacinas 5,10

O frio $\mathrm{cm}$ temperaturas situadas ao redor de $70^{\circ} \mathrm{C}$ negativos assegura a viabilidade de suspensões do vírus aftoso por períodos de tempo consideráveis ${ }^{4}$, no entanto a eficiência deste agente. isolado, é bastante reduzida, no tempo, a medida que a escala térmica situe-se em temperaturas superiores a $40^{\circ} \mathrm{C}$ negativos 6 .

O emprego do frio aliado à liofilizaçāo ou agentes químicos como o glutamato de sódio 6,7 , tem sido solução alternativa passivel de utilização em locais aonde temperaturas de congelamento da ordem de $70^{\circ} \mathrm{C}$ negativos não sejam disponiveis.

A glicerina tem sido largamente empregada como agente conservador em amostras biológicas enviadas ao laboratório com suspeição de etiologia viral $3,8,13,16,18$. Este produto, além de preservar os tecidos, apresenta poder bactericida e é capaz de baixar o ponto crioscópico de meios lí. quidos 12,15 .

Deste modo o estudo do emprego da glicerina como agente conservador que aliado ao frio pudesse garantir a viabilidade de suspensões do vírus da febre aftosa, por longos períodos de tempo, constitui-se no objetivo deste trabalho.

As hipóteses formuladas foram as seguintes:

Hipótese de Nulidade: - os resultados obtidos em titulaçōes de uma suspensão de virus da febre aftosa, realizadas em diferentes ocasiōes, em determinado espaço de tempo, não dependem da incorporação da glicerina ao diluente comum.

- Hipótese Alternativa: - os resultados obtidos em titulações de uma suspensão de vírus da febre aftosa, realizadas em diferentes ocasiões, em determinado espaço de tempo, são maiores quando a glicerina é incorporada ao diluente comum.

O nivel de significância adotado foi o de 0.05 .

\section{MATERIAL E MÉTODOS}

O vírus empregado, consistiu no tipo " $\mathrm{C}$ " Waldmann da febre aftosa, subtipo "C3" Indaial, obtido por passagens em cultivo de células $\mathrm{BHK}_{21}$ clone 13 .

O diluente utilizado foi a solução salina de Earle adicionada de 2.000 unidades internacionais de penicilina $G$ potássica e 2.0 miligramas de sulfato de estreptomicina por mililitro.

O sistema biológico utilizado nas titulações de vírus foi representado por camundongos suiços albinos, lactentes de cinco a se te dias de idade, distribuídos em grupos de oito individuos, acompanhados da respectiva mãe. 
A glicerina empregada foi o produto pró-análise, neutro, bidistilado (E. MERCK, Germany).

Os tratamentos realizados e as respectivas épocas de instituição são representados a seguir.

Partindo-se de uma mesma fonte de vírus, foram tomadas duas porções que receberam, respectivamente, igual volume, de glicerina, e de diluente, constituindo os tratamentos A e B. Cada um destes grupos foi homogeneizado e subdividido em cinco alíquotas iguais, quatro das quais foram levadas imediatamente ao congelador, sendo mantidas à temperatura de $20^{\circ} \mathrm{C}$ negativos até o momento da utilizaça. A quinta alíquota de cada grupo foi, nesta oportunidade, submetida à titulação, com dez repetiçðes, visando determinar o poder infectante de cada lote no in ício do experimento. As titulaçס̃es subsequentes, sempre em dez repetiçðes por vez, foram levadas a efeito, simultâneamente para cada tratamento, aos 117, 150, 185 e 213 dias.

Cada titulação foi realizada segundo a técnica de SKINNER e cols. 17 em diluições seriadas de razđo dez, inoculadas pela via intraperitonial em camundongos, na dose de 0,05 mililitros por animal. Os animais foram mantidos em observação por sete dias e a determinação do título foi realizada segundo o método de REED e MUENCH 14 .

A análise estatística dos resultados obtidos foi realizada segundo os princípios de GOLDSTEIN9.

\section{RESULTADOS}

Na Tabela 1, figuram os títulos infectantes, expressos em logarítmo de base 10 , das replicaçбes da prova de titulaçāo da suspensão do vírus " $C$ " Waldmann da febre aftosa de acôrdo com os tratamentos A e B e a época de sua realização. Aparecem também para cada tratamento e cada época de realização os valores da média aritmética, do desvio padrāo e do coeficiente de variabilidade de Pearson.

A regressão linear calculada para os dados da tabela 1 , levou a obtenção das equações de reta expressas por: $\mathbf{Y} \mathrm{A}=$ $7,2605-0,0154 X_{\text {e }} \widehat{Y}_{\mathrm{B}}=7,2080-0,0054 \mathrm{X}$, respectivamente para os tratamentos $A$ e $B$, aonde $X$ representa o tempo, em dias e $\hat{Y}$ o título médio infectante, em logarítmo de base 10 , da suspensão de vírus.

Os valores de t calculados, foram de -2,7364 e -8,5075, respectivamente, para os tratamentos $\mathrm{A}$ e $\mathrm{B}$, revelando a existência de regressðo de $\hat{\mathrm{Y}}$ em X para os dois tratamentos efetuados, ao nível de rejeição adotado.

No gráfico 1, figuram as retas de regressão segundo o tratamento. $O$ teste de significância para a diferença entre duas inclinaçðes 9 levou a conclusão de que há uma diferença significante $(\mathrm{p}<0,001)$ entre as inclinações das duas retas de regressão calculadas.

Os intervalos de confiança (95\%) para a média dos títulos da suspensão de vírus no dia zero, foram de 7,2605 $\pm 0,1719$ e $7,2080 \pm 0,1955$, respectivamente para os tratamentos A e B; o cálculo destes intervalos para a média dos títulos no dia 213 do experimento, apresentou valores de $6,9329 \pm 0,1230$ e $6,0570 \pm 0,1400$, respectivamente, para os mesmos tratamentos anteriormente citados.

\section{DISCUSSÃO}

Os resultados obtidos no presente estudo ressaltam alguns aspectos que convém discutir.

Os dados constantes da tabela 1 , demonstram que a titulação do vírus da febre aftosa, em camundongos, segundo a técnica de SKINNER e cols. 17 , apresenta boa reprodutibilidade, pois as medidas de dispersão calculadas nas diferentes repetiçôes de cada titulação, indicam variabilidade de resultados bastante reduzida.

A existência de regressão entre tempo de estocagem e título do vírus foi estatisticamente demonstrada $p<0,001$ para os dois tratamentos instituídos.

Contudo esta tendência apresenta uma diversidade de inclinaça em razão de cada um dos tratamentos adotados caracterizando a existência de duas populações distintas de vírus expressas pelos valores médios de seus títulos, obtidos durante o período de estocagem, conforme bem o demonstra a análise estatística $(p<0,001)$ efetivada pelo teste de significância entre duas inclinaçðes.

A confirmação da conclusão obtida pelo teste de significância de duas inclinações de retas de regressão pode ser obtida através dos intervalos de confiança $(95 \%)$ calculados para o dia zero e dia 213 do experimento.

Realmente, os títulos de vírus no dia zero, quando comparados entre os dois tratamentos realizados, apresentam uma dispersão de valores superponíveis, demonstrando que as concentrações de vírus, para os tratamentos A e B, no início do experimento, pertenciam a uma mesma população.

No entanto quando se faz a mesma comparação com os resultados registrados no dia 213 do experimento, constata-se que não há superposição entre os vảores relativos aos dois tratamentos efetuados, permitindo concluir-se que nesta ocasião os valores médios do título da suspensão vírica foram maiores para o tratamento A do que para o tratamento B.

Deste modo a análise estatística dos resultados obtidos leva a aceitar-se que nas condições do presente estudo os títulos de uma suspensão de vírus da febre aftosa, obtidos em provas de titulação sucessivas durante um determinado espaço de tempo foram significativamente maiores quando a esta suspensão foi incorporada a glicerina.

As conclusбes aqui obtidas, discordam daquelas referidas por BARYA e cols. 1 (1969) e por MACKOWIAK e cols. 11 (1954), que consideram pobre a atuação da glicerina na conservação do vírus da febre aftosa em materiais originários de animais. Esta discordância poderia ser atribuída à variação na qualidade e pureza de partidas de glicerina, conforme citado por BLANC e cols. ${ }^{2}$ (1947) ou mesmo por te- 
rem os referidos autores empregado substrato para multiplicação viral diferente daquele utilizado neste experimento.

ROZAS, CEF - CORTES, J A - VASCONCELLOS, S. A ; ITO, F.H Use of glycerine as an auxiliary element for the storage of foot and mouth disease virus. Rev.Fac.Med.vet.Zootec.Univ.S. Paulo, 18(2): 147-151, 1981.

SUMMARY: Two fractions of the same Type "C" Waldmann, subty. pe "C3" Indaial foot-and-mouth diseasc (FMD) virus suspension were added respectively to equal volume of glycerine and an ordinary diluent (Earlc's saline containing 2,000 UI of penicillin G and 2,0 miligrams of stretomycin per mililiter), and stored at $-20^{\circ} \mathrm{C}$. The results obtained at $117,150,185$ and 213 days af ter their preparation by means of replicated consecutive titration test using suckling mice, showed higher stability for the glycerine-added suspension.

UNITERMS: Glycerine*; Foot-and-mouth disease, virus*.

\section{REFERENCIAS BIBLIOGRĀFICAS}

1- BARYA, M.A.; AFZAL, H.; QURESHI, M.S. Effect of storage at $-20^{\circ} \mathrm{C}$ on the infectivity of foot-and-mouth disease virus type 0 . Bull. Off.int.Epiz., 71(5/6):847-52, 1969.

$2-$

BLANC, R.A. Conservacion del virus aftoso en glicerina al $50 \%$ en medio de Vallee y por congelacion. Rev.Med.Vet., B. Aires, 29:831-9, 1947.

3- BROOKSBY, J.B.; DAVIE, J.; HEDGER, R.S. Transmission of virus samples. Bull.off.int. Epiz., 61(11/12):1605-15, 1964.

4- CECCARELLI, A. Conservazione a basse temperature del virus aftoso contivato in vitro su cellule renali. Zooprofilassi, 15:33-6, 1960.

$5-$

ESPINET, R.G. Importancia de las cantidades de DI50 de virus infectadas en los bovinos testigos y vacunados en el indice $\mathbf{K}$, segun los diferentes titulos de partida del virus de prueba, como factor de error que afecta al grado de confiabilidad del sistema. Gac.vet., B. Aires, 32(243): 443.54, 1970.

FAYET, M.T. Conservation du virus aphteux congelé. Rev.Immunol., Paris, 28(4/5):277-84, 1964.
7-

FELLOWES, O.N. Infectivity stability of foot-and -mouth disease virus in certain mediuns at various temperatures. Amer.J.vet.Res., 23: 1035-40, 1962.

8- GARCIA PIRAZZI, A.J. Conservacion del virus aftoso en medio Vallee, glicerina al $50 \%$ y por congelacion. Gac.vet., B. Aires, 14(80): 243-6, 1952.

9- GOLDSTEIN, A. Bioestatistics: an introductory text. 2.ed. New York, Mc Millan, 1965.

10- LUCAM, F.; FEDIDA, M.; DANNACHER, G. Los "errores" del indice $\mathrm{K}$ debidos a las diferencias de titulo del virus de prueba. Gac.vet., B. Aires, 33(249):129-31, 1971.

11- MACKOWIAK, C.; GIRARD, H.; LANG, R. Procédés de conservation du virus aphteux de culture. Ann.Inst. Pasteur, 87:465-8, 1954.

12- MERYMAN, H.T. General principles of freezing and freezing injury in cellular material. In: Freezing and drying of biological materials. Ann.N.Y.Acad.Sci., 85:503-9, 1960.

13- QUIROGA, S.S. \& SCHANG, P.J. Observaciones experimentales sobre la conservacion del virus aftoso. In: JORNADAS AGRONOMICAS Y VETERINARIAS DE LA FACULTAD DE AGRONOMIA Y VETERINARIA DE BUENOS AIRES, 1939.

14- REED, L.J. \& MUENCH, H. A simple method for estimating fifty percent end points. Amer.J.Hyg., 27:493, 1938.

15- REY, L.R. Thermal analysis of entectics in freezing solutions. In: Freezing and drying of biological materials. Ann.N.Y.Acad.Sci., 85: 510-34, 1960.

16- ROSSI, F.A. Metodo practico para el envio y conservacion de los virus aftosos. Gac.vet., B. Aires, 9(47):147-52, 1947.

17- SKINNER, H.H.; HENDERSON, W.M.; BROOKSBY, J.B. Use of unweaned white mice in footand-mouth disease research. Nature, London, $169: 794-7,1952$.

18- SEHGAL, C.L. Studies on foot-and-mouth disease. IV. Development of improved methods 
for the preservation os standard strains of Recebido para publicação em: 10-10-80 foot-and-mouth disease virus. Indian J.anim. Sci., 41(5):331-2, 1971.

GRÁFICO 1 - Retas de regressão dos títulos de suspensão de vírus tipo "C" Waldmann da febre aftosa, expressos em logaritimo de base 10 , em função de tempo, em dias e de acôrdo com o tratamento empregado§. São Paulo, 1980.

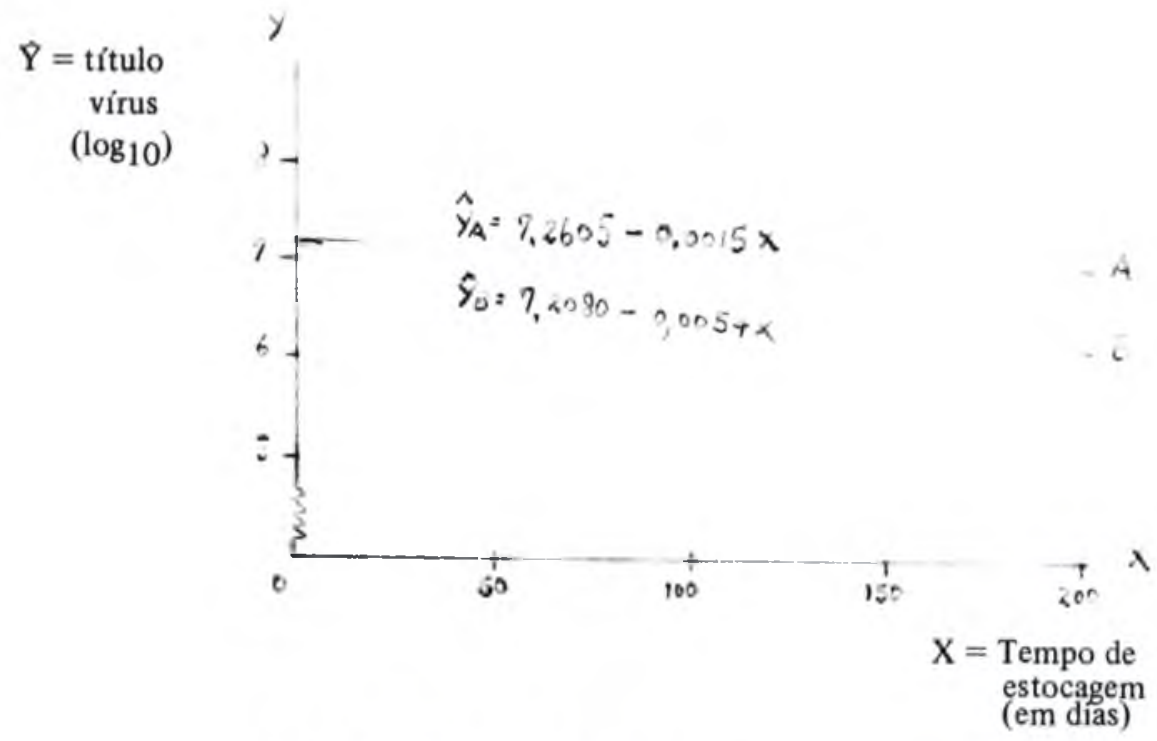

$\S \mathrm{A}=$ glicerina; $\mathbf{B}=$ diluente 
TABELA 1 - TItulos infectantes expressos en logaritmo de base 10, das replicações da prova de t1tulação da suspensäo de virus tipo "C" WALDMAN da Febre Aftosa, realizada em camundongos, segundo os Tratamentos A e B e a época de sua realização. São raulo, 1980.

\begin{tabular}{|c|c|c|c|c|c|c|c|c|c|c|}
\hline \multirow{2}{*}{$\underbrace{\text { TRATAMENTO estocagem }}_{\begin{array}{c}\text { Replicaçōes } \\
\text { da Titulação }\end{array}}$} & \multicolumn{5}{|c|}{ A (GLICERINA) } & \multirow[t]{2}{*}{$B$} & \multicolumn{4}{|c|}{ (DILUENTE) } \\
\hline & 0 & 117 & 150 & 185 & 213 & & 117 & 150 & 185 & 213 \\
\hline 1 & 6,96 & 6,82 & 6,20 & 6,55 & 6.60 & 6,89 & 6,10 & 5,68 & 5,93 & 5,67 \\
\hline 2 & 7,10 & 6,82 & 6,30 & 6,65 & 6,70 & 6,89 & 6,40 & 5,82 & 5,94 & 5,80 \\
\hline 3 & 7,18 & 6,92 & 6,63 & 6,86 & 6,89 & 7,01 & 6,41 & 5,96 & 6,18 & 5,88 \\
\hline 4 & 7,18 & 6,98 & 6.86 & 6,88 & 6,89 & 7,07 & 6,41 & 6,00 & 6,30 & 6,05 \\
\hline 5 & 7,30 & 7,01 & 6,88 & 6,93 & 6,94 & 7,30 & 6.63 & 6,08 & 6,30 & 6,11 \\
\hline 6 & 7,30 & 7.08 & 7,03 & 7,01 & 7,01 & 7,30 & 6,65 & 6,18 & 6,40 & 6,20 \\
\hline 7 & 7,40 & 7,16 & 7,03 & 7,10 & 7.16 & .30 & 6,71 & 6.18 & 6,42 & 6,20 \\
\hline 8 & 7,50 & 7,16 & 7,17 & 7,16 & 7,42 & 7,50 & 6,73 & 6,20 & 6,55 & 6,31 \\
\hline 9 & 7,63 & 7,18 & 7,18 & 7,18 & 7,50 & 7,63 & 6,76 & 6,30 & 6,59 & 6,50 \\
\hline 10 & 7,73 & 7,18 & 7,55 & 7,40 & 7,58 & 7,90 & 6,80 & 6,63 & 6,96 & 6,52 \\
\hline $\bar{x}$ & 7,32 & 7,03 & 6.88 & 6,97 & 7,06 & 7,38 & 6,56 & 6,10 & 6,357 & 6,124 \\
\hline $\mathbf{s}$ & 0,298 & 0,1358 & 0,391 & 0,241 & 0,319 & 0,3133 & 0,2093 & 0,304 & 0,292 & 0,321 \\
\hline $\mathrm{CV} 8$ & 4,2 & 1,93 & 5,68 & 3,46 & 4,51 & 4,42 & 3,19 & 5,04 & 4,59 & 5,24 \\
\hline
\end{tabular}

$\overline{\mathrm{X}}=$ Mëd1a aritmētica

$S=$ Desvio Padräo

CV8 = Coeficlente de Varlabilidade de Pearson expresso em porcentarem. 